\title{
Comparative study of behaviour of reinforced concrete beam-column joints with reference to monolithic and non-monolithic connection
}

\author{
Ninik Catur Endah Yuliati ${ }^{1,2, *}$, Dewi Sri Murni ${ }^{2}$, Wisnumurti ${ }^{2}$, Wibowo Ari ${ }^{2}$ \\ ${ }^{1}$ Civil Engineering Department, University of Merdeka Malang, Malang, Indonesia \\ ${ }^{2}$ Civil Engineering Department, University of Brawijaya, Malang, Indonesia
}

\begin{abstract}
The implementation method of reinforced concrete construction has progressed very rapidly. This development aims to speed up time and reduce costs. One of the most widely used methods is the precast method, but the less popular precast method is used for simple storey buildings. Therefore, in this study the semi-precast method, which is easy to implement in a simple storey building, was presented. Parts of columns and beams were cast in place with different casting times. Therefore, the connection become non-monolithic. This study presented a comparison between the deflection and the static load capacity that can be received by the connection of reinforced concrete beam-column which is monolithically connected and non- monolithic. 3 sets of specimens were made to represent monolithic and non-monolithic specimens. The nonmonolithic specimens were made with 2 models, i.e. without and with a notch. The beam-column connections were tested experimentally and compared to the monolithic beam-column connection. The results showed that the notch on non-monolithic test specimens can increase the load capacity and reduce deflection compared to the specimen test without notch. The experimental results also showed that the strength and performance of structural non-monolithic beam-column connections were as good as those of monolithic beam-column joints.
\end{abstract}

\section{Introduction}

The method of implementation of reinforced concrete construction has progressed very rapidly. This development aims to speed up time and reduce implementation costs. One of the most widely used methods is the precast method, but the less popular precast method is used for simple storey buildings. Therefore, in this study the semi-precast method, which is easy to implement in a simple storey building, is presented. Parts of columns and beams are casted in place with different casting times. Therefore, the connection between columns and

\footnotetext{
* Corresponding author: ninik.catur@unmer.ac.id
} 
beams becomes non-monolithic. A common problem with non-monolithic beam-column connection was the reduced structural stiffness that can lead to decreased strength and performance of reinforced concrete structures. This study aims to improve the performance and strength of the non-monolithic beam-columns joint due to separate casting. Separate casting methods on this beam and columns adopt the widely used slip-forming method in high-rise reinforced concrete buildings. Some studies of the slip-forming method indicate that the performance of a non-monolith beam-column joint can be improved so that it can be the same as a monolith beam-column joint.

The moving formwork construction method is a representative method of using a movable form of the continuous construction of a concrete structure. The advantages of this method are the rapidity of work, high productivity and reduction in costs. The type of structure that suits this method is the core of tall buildings, silos, telecommunication towers, cooling towers, heavy concrete offshore platforms, etc. Research conducted by Zayed, et al. [1] regarded the application of moving formwork method in the construction of cores and silos. The objective is to assess the productivity, to determine the appropriate speed, and to combine the additional resources. The results show that the simulation model developed can predict the project's productivity up to $99.70 \%$ and $99.30 \%$ accuracy. The results of this study greatly helped to schedule and manage the resources needed for practitioners.

Research conducted by Khalek, et al. [2] aims to determine the most effective parameters affecting the duration of moving formwork operations. The proposed model performance was validated by comparing simulation model results of real case studies showing an average accuracy of $98.7 \%$. The moving formwork method can be used for smaller structures. The advantages of this method are the speed of erection, the absence of cold connections, the control of good workmanship and improvement, and labor savings. Successful moving formwork relies on efficient management of 3 main parameters; concrete, delivery system and formwork.

The key is to control the time of fresh concrete arrangement so that the shape can be lifted at a given speed [3]. Based on the results of previous research, is the underlying experiments carried out regarding the non-monolith column beam joints. The column section is assumed to be worked by moving formwork method, while the beam section is cast in the site after 1 day.

\subsection{The beam-column joint in precast structures}

The connection between elements of building construction serves to integrate the elements of the building structure to become a monolithic unity so that it can stabilize building structure. The application of moving formwork method results in a non-monolithic connection. This type of connection resembles a wet connection to a pre-cast system. The wet joint comprises the removal of the reinforcing steel from the edges of the column components and the interconnected bars are connected with the aid of the mechanical joint, and the length of the discharging. This type of connection works well to reduce the stress increase due to crawling, shrinkage and temperature changes. This wet joint is highly recommended for buildings in earthquake-prone areas because it can make each component of concrete into a semi-monolith.

According to Breccoletti, et al. [4], precast use has several advantages over cast-in-site such as lower production and cost times, as well as better quality control. However, precast is usually difficult to behave as SRPM as in the cast in-site system. In this paper, technical solutions are provided to ensure continuity between beams and columns by providing missile connections and casting with fiber concrete to increase tensile ductility of the concrete on the wet part of the joint. HBK precast test specimens were compared with HBK 
monolithic test specimens. The test results show that the precast structure behaves as expected both in terms of strength and ductility.

The research of Ghayeb, et al.[5] showed that in the precast connections reinforced steel plate, displacement, shift ratio, and elastic range were higher when compared with monolithic joints. This is seen from the value of tensile stress and high ductility. The drift ratio also increased between 1.3 until 1.9 when compared to monolithic connections. Ghayeb recommended that the decrease in strength in non-monolithic connections should not exceed $20 \%$.

\subsection{Connection of beam-column}

The beam joints of the columns are the most critical areas in the design of a reinforced concrete frame. In the RC structure, the beam-column connection function is to transfer the load from connecting members effectively, while experiencing seismic excitation. Shared beams can be defined as part of a column in the depth of the deepest beam that frames into a column. Based on its location, the column-beam relationships can be grouped into three types, namely: exterior connections, interior connections, and corner connections [6]. In this study a case example is taken of the corner connection.

According to Park and Paulay [7], the principle of connection planning in precast elements can be classified into two categories, namely: (a). Strong Connection, when joints between precast elements still behave elastically during a strong earthquake. This connection system is proven theoretically and experimentally has the strength and hardness as the monolithic concrete structure. (b). Connection Ductile, when the connection undergoes inelastic deformation, the system connection must be proven theoretically and experimentally to meet the reliability requirements and stiffness of earthquake resistant structures.

Pauletta et al. [8] have proposed a model to determine the shear strength of exterior HBK reinforced concrete to receive earthquake loads. The explicit formula assumes the contribution of shear strength given by the strut-and-tie mechanism due to the two diagonal tensile forces of the concrete, as well as the reinforcement of the steel reinforcement. In the exterior HBK, shear reinforcement in the form of horizontal shear reinforcement provides more effective reinforcement when compared to vertical shear reinforcement.

Based on the results of previous research, which shows that the use of moving formwork method can reduce time and save costs than the research done with laboratory scale. 3 sets of specimens were made to represent the connection of columns of monolithic and non-monolithic specimens. The non-monolithic column beam connections are made with notches and without notches. The shear strengthening is applied to the junction section of the beams and columns as recommended by Pauletta et al.[8]. Each condition of the beam columns relationship made 3 specimens.

\section{Material and experimental program}

\subsection{Material}

The size of the tested beams and columns are shown in the Table 1. 
Table. 1. Description of beam-column connection specimens.

\begin{tabular}{|c|c|c|}
\hline Description & Beam & Column \\
\hline Dimensions $(\mathrm{mm})$ & $150 \times 200 \times 1000$ & $200 \times 200 \times 750$ \\
\hline $\mathrm{fc}(\mathrm{MPa})$ & 21 & 21 \\
\hline $\begin{array}{c}\text { Longitudinal } \\
\text { reinforcement }\end{array}$ & $4 \emptyset 13$ & $4 \emptyset 13$ \\
\hline Stirrup & $\emptyset 8-100$ & $\emptyset 10-100$ \\
\cline { 2 - 3 } & $\emptyset 8-50$ & $\emptyset 10-50$ \\
\hline
\end{tabular}

Classification of beam-column connection specimens is shown in the table 2.

Table 2. Classification of beam-column connection specimens.

\begin{tabular}{|c|l|c|c|}
\hline No. & \multicolumn{1}{|c|}{ Specimen } & Number of specimens & Code of specimens \\
\hline 1 & Monolithic & 3 & SK-A0 \\
\hline 2 & $\begin{array}{l}\text { Non-monolithic without } \\
\text { notches }\end{array}$ & 3 & A0-B0 \\
\hline 3 & Non-monolithic with notches & 3 & A0-B1 \\
\hline
\end{tabular}

\subsection{Experimental program}

The experimental program includes a total of three sets of specimens of RC beam-column connection. The test specimen is based on design criteria according to SNI 2847-2013 [9] and ACI 318-14 [10]. Each specimen was tested by providing a static load with a $50 \mathrm{~kg}$ load interval until it reached collapse. The deflection occurring on the beam is measured by installing LVDT at a distance of $200 \mathrm{~mm}$ and $1000 \mathrm{~mm}$. Strain due to the bending stress and shear stresses that occur in the concrete is measured by installing a dial gauge. Strain occurring on longitudinal reinforcement and stirrups is measured by installing a steel strain gauge on longitudinal reinforcement and stirrups. The reinforcement detail can be seen in the following figure:

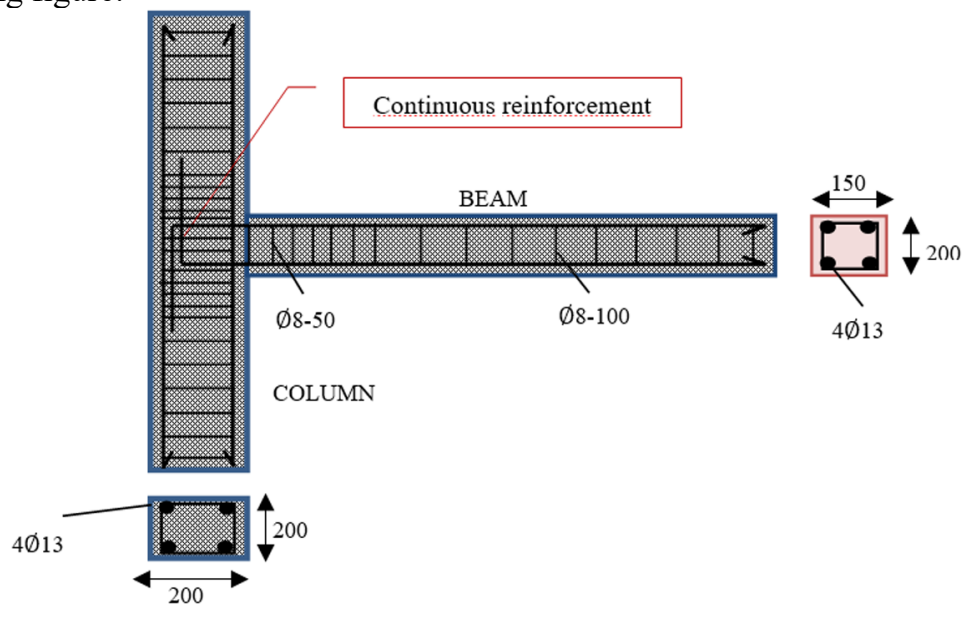

Fig. 1. Reinforcement of a monolithic specimen. 

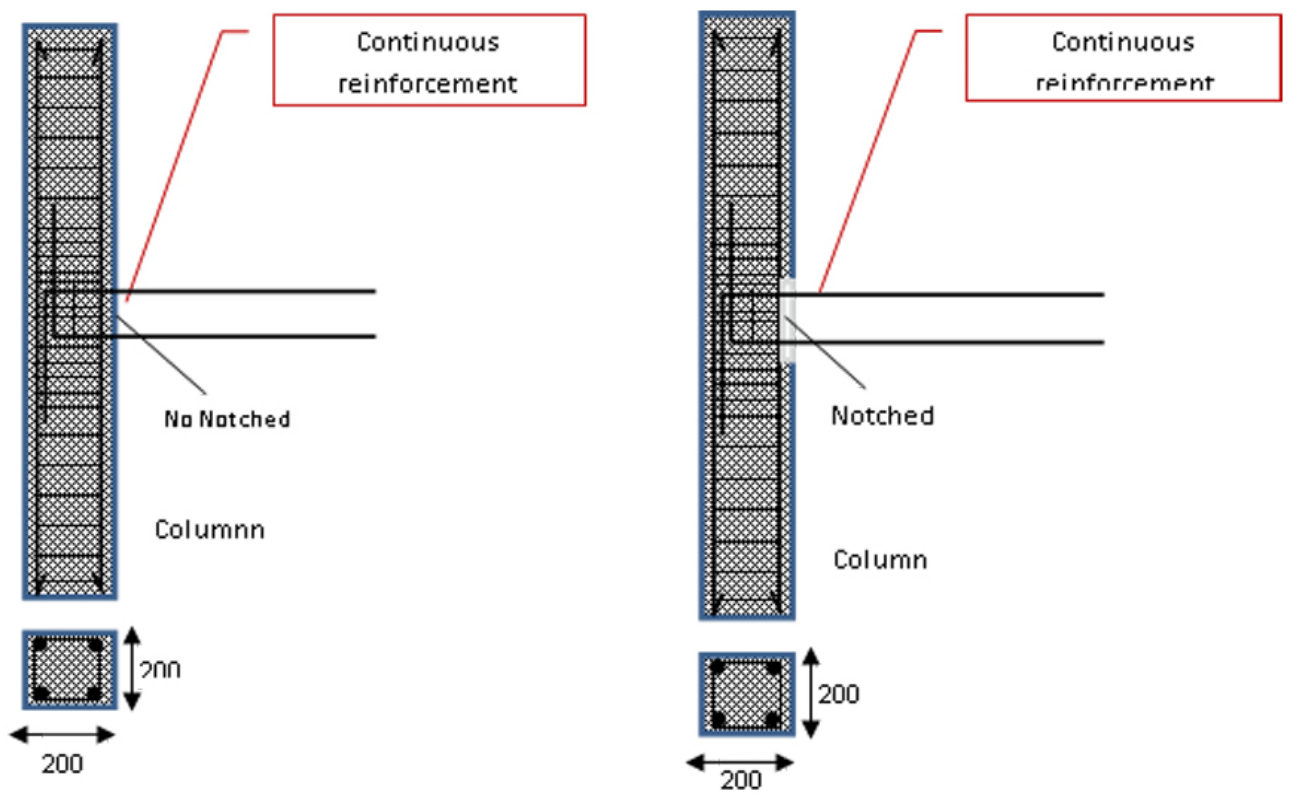

Fig. 2. Reinforcement of a non-monolithic specimen.

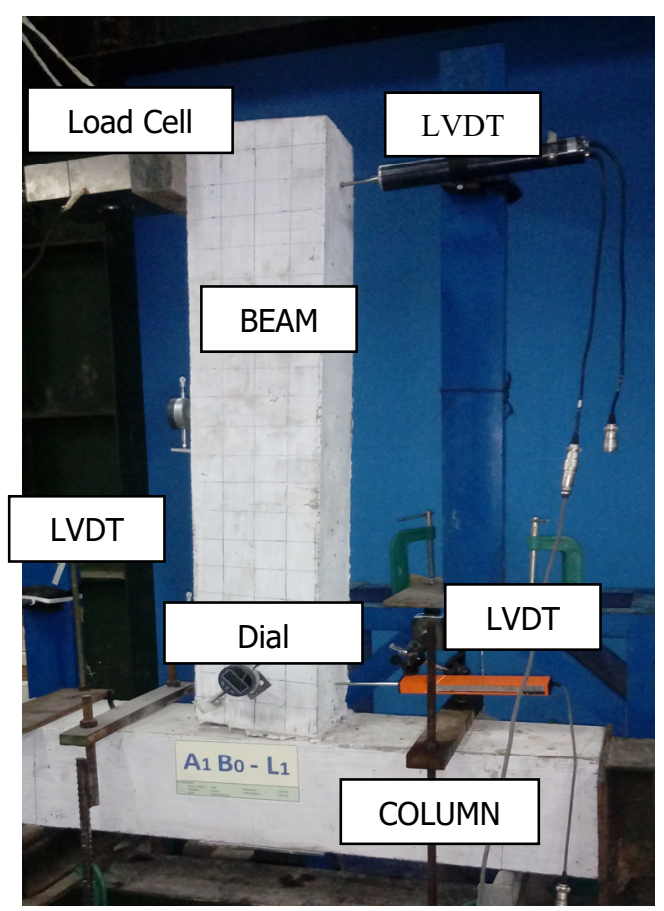

Fig. 3. Test set up. 


\section{Results and discussion}

\subsection{Load capacity}

Based on the result of the test, it was found that in the non-monolithic beam-column joint connection without notches, the maximum acceptable load capacity decreased compared to the monolithic connection. The magnitude of the decline was $17 \%$, i.e. $1686 \mathrm{~kg}$ for monolithic connection and $1394 \mathrm{~kg}$ for non-monolithic connection without notches. However, given a notch that can serve as an additional shear field can increase the load capacity of the acceptable up to $11 \%$, to $1547 \mathrm{~kg}$. The same phenomenon also occurs in the load capacity as the first crack occurs. The first cracks occur at $1150 \mathrm{~kg}, 950 \mathrm{~kg}$, and 1100 $\mathrm{kg}$ loads for monolithic connections, non-monolithic connection without notches and nonmonolithic connections with notches. The loads that can be received by each specimen can be seen in figure 4 below.

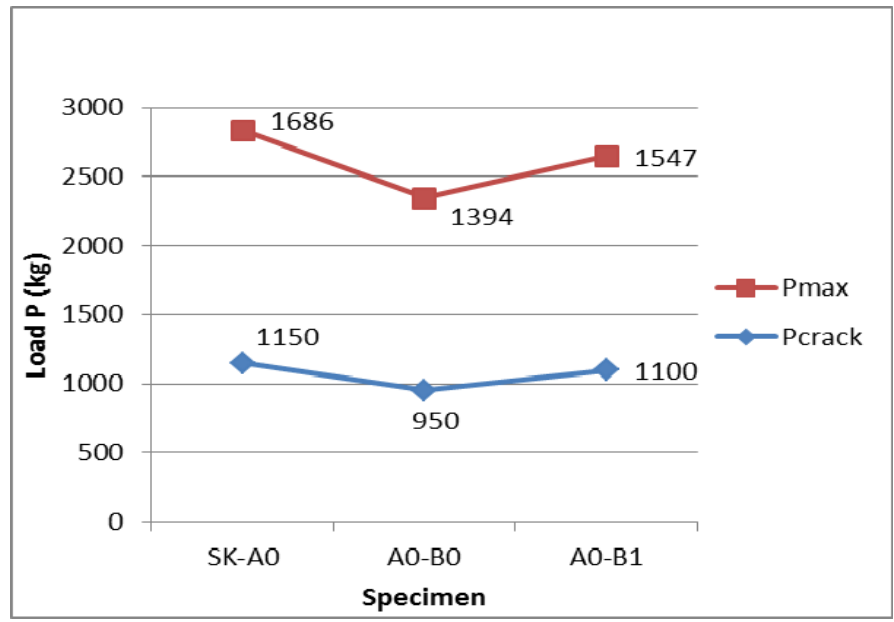

Fig. 4. Maximum load and crack load on each specimen.

\subsection{Deflection and ductility}

Based on the test results, it can be seen that the deflection that occurs in non-monolithic connection without notches has a considerable increase compared to the monolithic connection. This clearly indicates that monolithic connections are more rigid than nonmonolithic connections. The presence of notch given to the non-monolithic connection has an effect on the increase in the visible connection stiffness of the deflection. The correlation between the load and the deflection that occurs can be seen in Figure 5 below.

The correlations between the deflection occurring at the first crack of the maximum deflection indicate the degree of ductility of the specimen. The change of ductility value of the specimens can be seen in figure 6 below. 


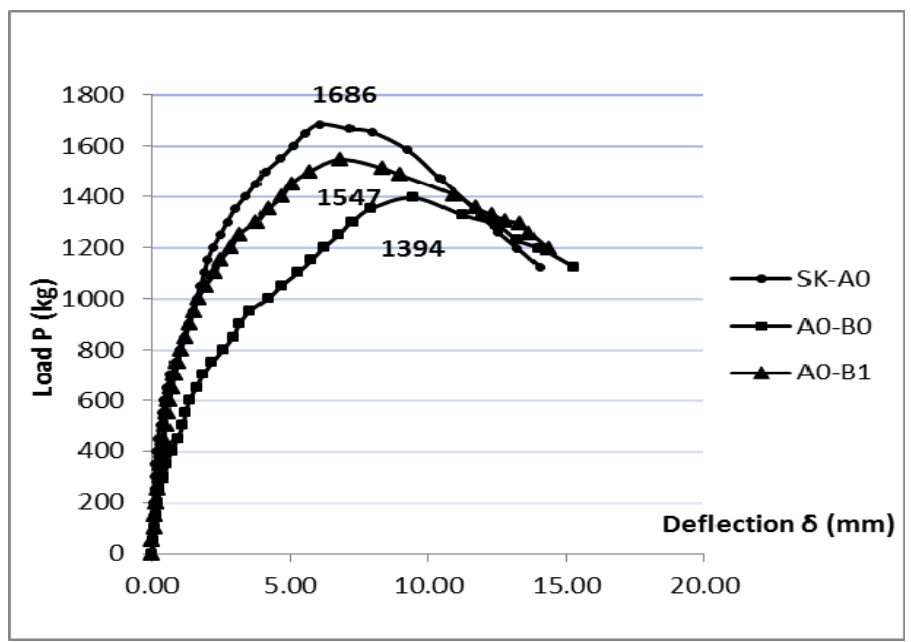

Fig. 5. Load and deflection correlations.

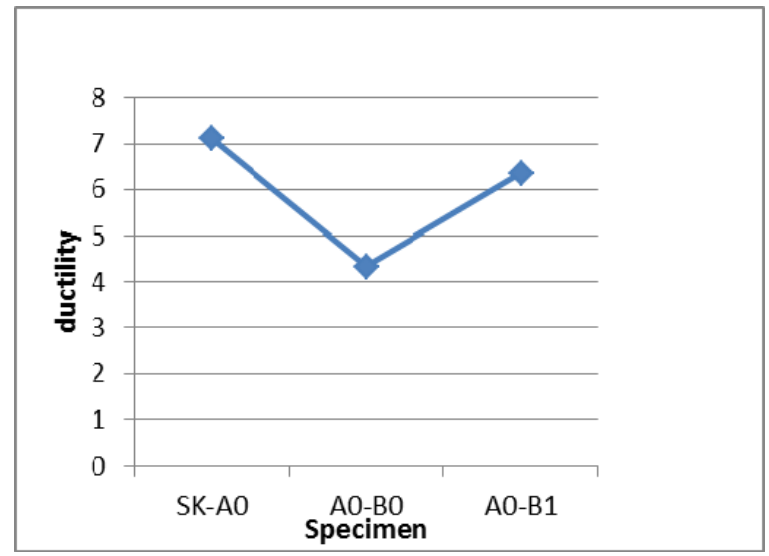

Fig. 6. Ductility of each specimen.

\subsection{Crack patterns}

Crack patterns that occur after receiving a static load differ on each specimen. In the monolithic specimens, the crack propagation occurs slowly until the peak load and collapse occur. Initial cracking occurs when working load of $1150 \mathrm{~kg}$ is applied. Crack propagation that occurs on the beam continues to grow and extend along with increasing load. Crack propagation on the beam stops when cracking occurs at the interface of the beam and the column causing the opening. The collapse occurs when the crack is very large and towards the column area and there is considerable damage to the beam compression area. Crack patterns and damage to monolithic specimens can be seen in figure 7 . 

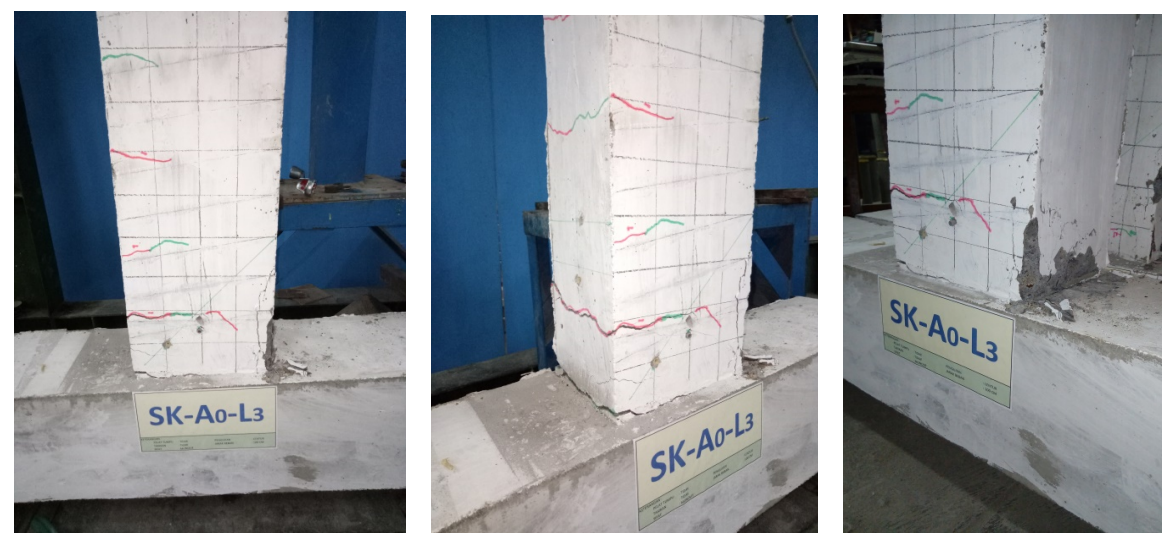

Fig. 7. The crack pattern of the monolithic specimen.

In non-monolithic specimens without notches, the crack propagation occurs very quickly until peak load and collapse occur. Initial cracking occurs when a working load of $950 \mathrm{~kg}$ is applied. Crack propagation that occurs on the beam does not increase but extends along with the increase in load. Crack propagation on the beam stops when cracking occurs at the interface of the beam and the column causing the opening. The collapse occurs when the crack in the column beam encounter reaches half the height of the beam. Cracks also do not occur in the column, and there is no significant damage to the beam compression area. Crack patterns and damage to non-monolithic specimens without notches can be seen in figure 8 .
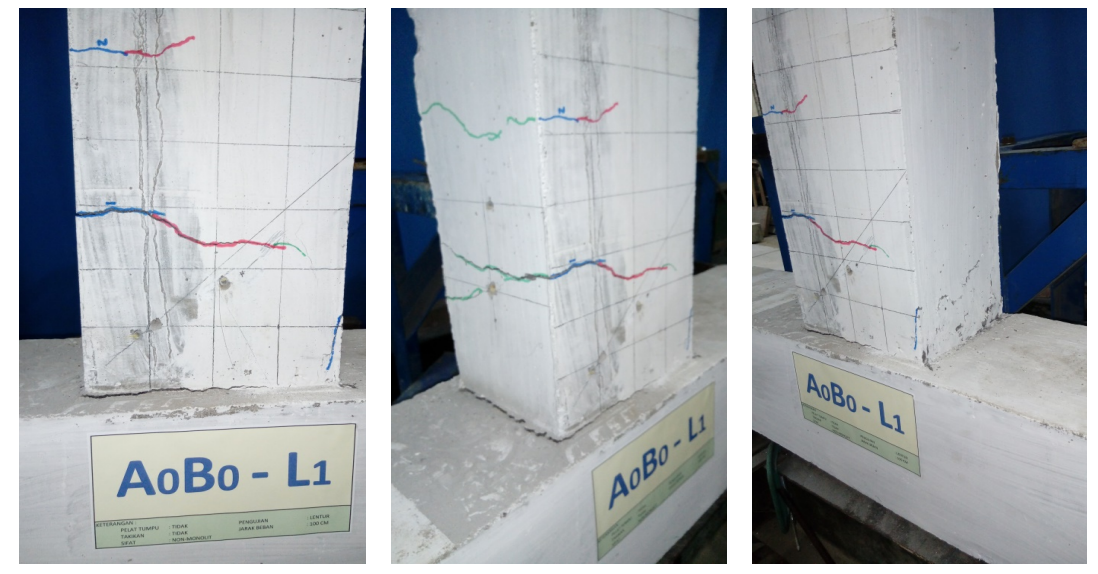

Fig. 8. The crack pattern of the non-monolithic specimen without notches.

In non-monolithic test specimens with notches, the crack propagation occurs slowly until the peak load and collapse occurred. Initial cracks occur when working loads of 1100 $\mathrm{kg}$ are applied. Crack propagation that occurs on the beam continues to grow and extend along with increasing load. Crack propagation on the beam stops when cracking occurs at the interface of the beam and the column causing the opening. The collapse occurs when the crack is very large and towards the column area and there is damage to the beam hit area. Crack patterns and damage to monolithic specimens can be seen in figure 9 . 

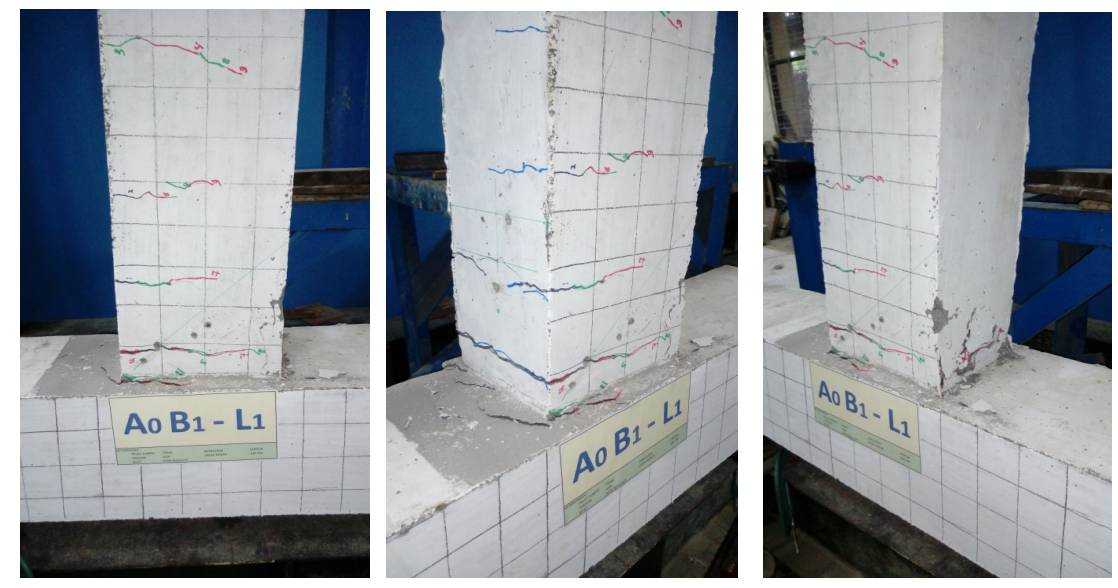

Fig. 9. The crack pattern of the non-monolithic specimen with notches.

\section{Conclusion}

Based on the data analysis and discussion, it can be concluded that the connection of beams and columns in simple-storey building structures can be done by casting in a separate place. The non-monolithic connection that occurs between the beams and columns lead to decreased load capacity, stiffness, and structural ductility compared with monolithic. The experimental results showed a decline of $17 \%, 23 \%$, and $38 \%$, respectively. The decrease in the performance of this beam-column joint can be improved by providing a notch in the column. This notch has a function as an addition to the shear area that can improve the stiffness of the beam-column joint. With the addition of this notch, improved performance of the beam-column joint was obtained in the form of increased load capacity, stiffness, and structural ductility compared with non-monolithic without notch. The increase was $11 \%$, $18 \%$, and $32 \%$, respectively. The experimental results also show that the strength and performance of structural non-monolithic beam-column connections with notch are as good as those of monolithic beam-column joints.

This research was conducted at the University of Brawijaya for a laboratory experiment with a grant program of BPPDN University of Brawijaya, Malang, Indonesia, and the research grant program of The Ministry of Research, Technology and Higher Education of the Republic of Indonesia

\section{References}

1 T. Zayed, M. R. Sharifi, S. Baciu, M. Amer, J. Constr. Eng. Manag., 134, 157-168 (2008)

2 H. A. Khalik, S. Khoury, R. Azis, M.A.Hakam, Am. J. Civ. Eng., 3, 9 (2015)

3 K. T. Fossa, Slipforming of Vertical Concrete Structures, 1292 (2001)

$4 \quad$ M. Breccolotti, S. Gentile, M. Tommasini, A.L. Materazzi, M.F. Bonfigli, B. Posqualini, V. Colone, M. Gianesini, Eng. Struct., 127, 129-144 (2016)

5 H. H. Ghayeb, H. A. Razak, and N. H. R. Sulong, Constr. Build. Mater., 151, 258-278 (2017)

6 ACI Committee 352, Recommendations for Design of Beam-Column Connections in Monolithic Reinforced Concrete Structures (2002) 
$7 \quad$ R. Park and T. Paulay, Reinforced Concrete Structures (John Wiley and Sons, New York, (1974)

8 M. Pauletta, D. Di Luca, G. Russo, Eng. Struct., 94, 70-81 (2015)

9 SNI 2847, Persyaratan Beton Struktural untuk Bangunan Gedung (Badan Stand. Indonesia, Bandung (2013)

10 A. C. I. Committee et al., Building Code Requirements for Structural Concrete and Commentary (Aci 318M-05), 2003, (2005) 